UDC $81^{\prime} 42$

DOI: $10.17223 / 24109266 / 5 / 3$

\title{
CHARACTERISTIC FEATURES OF ADAPTED LEGAL TEXT
}

\author{
S.V. Pervukhina \\ Rostov state university of railway (Rostov-on-Don, Russian Federation). \\ E-mail: s_pervuhina@mail.ru
}

\begin{abstract}
Studies of adapted (or simplified) legal texts are greatly required among people without a legal education. The Plain English Campaign is becoming more and more popular abroad in the legal sphere. UNO and European Union start to issue their documents and legal acts in Plain English. In Russia such research also has practical and theoretical importance for writing documents and developing text linguistics.

Adapted legal text is viewed as secondary text. They can be divided into two types according to the theory of communication, namely text-copies and textreactions. This paper analyzes structural, semantic, discourse and pragmatic characteristics of adapted texts. Adapted texts state the meaning of terms, corelations of terms within a terminology system for non-specialists. Adapted text shapes scientific world map for a non-specialist. The source-text has legal power to state laws and measures of punishment for their breaking. Adapted text has a different pragmatics. It is aimed at explaining the law and informing the reader. Source-text and adapted text can exist in one discourse or in different discourses.
\end{abstract}

Keywords: adapted text; source-text; legal discourse; special science world map; pragmatics; lexical semantics.

\section{Introduction}

Legal text frequently becomes the subject of linguistic study, which has caused formation of a new direction - legal linguistics [1,2, etc.], and studying of the simplified or adapted texts in this sphere is getting more and more urgent, both in Russia and abroad [3]. This urgency is easily explained by the fact that it is important for nonspecialists to understand what the laws are about, and also legislative bodies are interested in creation of acts which are easy to understand. So, K. Williams gives an example of the first act which has been simplified, that is "the Law of Her Majesty on incomes and tax gathering" in 1997 [3: 195].

Now the United Nations documents are due to be adapted, for example the Declaration of human rights, European Union bills, etc. It is connected with the fact that English can be included in the group of hypercentral languages, and it has become a global lingua franka [4: 5]. The reason is that the English language is not a mother tongue for many members of the listed organisations, and it is difficult for them to understand tiny nuances of the complicated official style of legal documents. 


\section{Method}

The research was based on the interpretation approach, which highlighted most common difficulties in understanding authentic legal texts, and showed main directions of necessary transformations. It should be considered that adaptation is aimed at particular readership, so addressee's characteristic features often initiate those transformations.

\section{Data analysis}

Adapted text is usually viewed as secondary text created for readers who for some reasons cannot understand the source text. The sphere of application of adapted texts is wide enough: simplified texts can be found in school textbooks, graded readers, and also adapted special literature. Adapted texts are used in the situations where knowledge of a professional in any sphere is necessary for a nonspecialist. The considerable quantity of adapted texts can be found in medicine (these are the texts adapted for younger medical personnel and patients), in legal sphere (the comment to codes, a newspaper column "consultations at the lawyer's" etc.), at drawing up of internal instructions in company document circulation etc. In this article we will address to characteristics of legal adapted texts.

Adapted legal texts, as a rule, are comments to codes or regulations or an explanation of any legal issue in newspapers, magazines, Internet sites in a column "consultations at the lawyer's". According to the character of the communication, adapted texts can be of different modes. Some of them follow the structure of the source-text, and some of them comment only a part in the form of a dialogue between an expert and a nonspecialist. In the first case, adapted text represents secondary text-copy, and in the second it is seen as secondary text-reaction. We use the term "secondary text" after S.V. Ionova, who calls this way "any text of secondary representation which is formed as a result of semantic transformations of the text-basis" [5: 9]. Secondary texts retain coognitive and semantic elements of the source-text as a condition of text increment. Thus the composition of the text and the basic story lines can be saved in the secondary text (textscopies), or only some part of the information of the source-text can be marked, and the subsequent message will be developed on this basis (textsreactions) [6: 118-119].

The understanding of adapted text as secondary is important for its structural-semantic analysis and understanding of modes of transformation of its information. Working out of rules of construction of adapted texts for different groups of readers has a significant practical value: special scientific knowledge of legal sphere is in demand by a wide groups of readers without the legal education. 
In this research we analyzed the following comments: the comment to the Constitution of the Russian Federation, the criminal code, the labour code, the Code of Administrative Offence of the Russian Federation, the Civil code, the Family code, and also comments of lawyers to decisions in housing and communal services sphere. We have analysed structural, semantic and discourse and pragmatic features of adapted texts. We will examine them consistently.

Judging by its structure, text-copy repeats the source text: division into chapters and paragraphs is saved, the sequence of its paragraphs is preserved. Text-reaction is an answer to a legal issue concerning only a part of a larger document (the code or decree). In both cases the attention in adapted texts is concentrated on any concept of the source-text and its further conceptual increment. In V.G. Gak's works it is noticed, that "the statement is a situation sign" (cit. on [7: 490]). The referential situation in the source-text and adapted text is the same, but the reference to this situation is different. The source-text written for experts in legal sphere appeals to a referential situation by a one-word nomination or a nomination by a word-combination, and adapted text created for a nonspecialist addresses to this referential situation by a nomination with much more complex structure (a predicative nomination or a super-phrase unity nomination).

Considering appeal methods to a referential situation, we have noted the following structural-semantic changes of adapted text: an explanation of terminology which can be unfamiliar to readers, attaching a certain meaning to the given term in the text, and also explication of significative semes and presuppositions.

For example, article 61 of the Budgetary code "Tax incomes of budgets of settlements" is devoted to tax gathering, and in the comment it is called "Tax incomes of local budgets". The adapted text of the article changes the composition of the article of the source-text, showing its structure:

"In the article commented the structure of tax incomes of local budgets is defined:

1) own tax incomes of local taxes and tax collections;

2) deductions from federal and regional regulating taxes and tax collections;

3) State Tax".

Such link is necessary for the reader who wishes to understand quickly what it is written about in a bigger article, and to decide, whether there is necessary information for them in it. This structural-semantic change of the text is directed to achievement of the pragmatical purpose: the comment to the Budgetary code can be used as help materials about the legislation of this field of activity.

In the source-text local taxes are mentioned, and their sources are enumerated: "tax incomes of the following local taxes established by repre- 
sentative bodies of settlements according to the legislation of the Russian Federation about taxes and tax collections... are enlisted in budgets of settlements». In the adapted text of the comment there is a definition of local taxes, and besides, it reveals sources of their funds raising: "The taxes and tax collections established in the Tax Code of the Russian Federation and standard legal acts of representative bodies of local government, installed according to the Tax Code of the Russian Federation standard legal acts of representative bodies of local government and obligatory to payment on territories of corresponding municipal unions. Local taxes and tax collections in federal cities Moscow and St.-Petersburg are established and installed by laws of the specified subjects of the Russian Federation". In the given example the meaning of the term "the local tax", is explicit, and its significative semes of this term are fixed. Also in this example there is a link to the Tax Code which contains the additional important information for this question. It is necessary to mention, that the source-text, owing to the pragmatists of the law-stating document, is very exact: concrete references to other bills with numbers of laws and dates of their coming into force whereas adapted text whose pragmatics is directed to acquaintance with a situation, does not offer such exact data.

In adapted texts-reactions the structural changes are evidently expressed: they do not repeat a source-text composition (the code or the law on which basis adapted text is created), and they are built around one or several points. It is possible to observe, that the description of a referential situation in adapted text becomes very detailed and adhered to the real situation which has occurred in life, and the source-text (the code) plays a role of a necessary context on which basis interpretation of concrete points is conducted.

The terminology explanation (or denotate explication) occurs in comments to codes for establishment of terms framework, where a certain meaning is attached to the given term or position. It is important for elimination of ambiguity of interpretation of terms or positions in legal documents.

Thus, to reach unambiguity of interpretation, it is necessary to lengthen the text to describe in much detail the legal situation which is mentioned in the code. Denotate explication also serves to shape specially-scientific picture of the world for a nonspecialist by means of adapted text. Fastening of conceptual value to the term occurs not in the source-text, but, as a rule, in adapted text of the comment or the text-reaction.

Explication of significative semes and presuppositions are important for creation of necessary context for understanding of any information in the code. We use the term "presupposition" to denote a certain preliminary knowledge (N.D. Arutyunova, V. Dejk). L.A. Naumova notes, that "making the statement about this or that subject (phenomenon), consciously or unconsciously, the speaker shows any already existing knowledge of this subject (phenomenon). Each statement supposes or assumes a judgement" [8: 237]. 
Presuppositions may concern explications of legal positions or logic of a reasoning which explains this or that legal situation and algorithm of actions in it. Such presuppositions can be called intradisciplinary presuppositions since they do not fall out of the limits of one subject sphere, in this case legal. Or it can be interdisciplinary presuppositions which create background knowledge for a lawyer, necessary for correct actions in this or that situation. These presuppositions concern not only legal discourse, but they involve knowledge of another subject sphere. It is possible to observe overlapping of specially-scientific language pictures of the world in a zone of these presuppositions. For example, in the criminal code a number of articles and offences are connected with deliberate or unintentional actions, and also with actions in an affect status. The comment to this code involves a psychological term for interpretation of a status of affect or intention. So, knowledge of psychology makes a necessary part of presuppositions for understanding of the articles of a code.

At the expense of an explication of the additional information in the adapted legal text, an immense text increment is observed. If adapted belles lettres texts show compression of the information which is aimed at increase of the text comprehension, here the situation is quite different: additional information is used to foster text comprehension, this information involves the adjacent fields of activity that increase the length of adapted legal text.

It is important to note discourse-pragmatical features of adapted legal text, in comparison with its source-text. In spite of the fact that both code text and its comment belong to legal discourse, these documents possess various pragmatical force. The code text states the law, so its pragmatics is aimed at establishment of rules of law and models of behaviour which are comprehensible in society, or punishment for infringement of these norms. The comment text, as well as texts in a column "consultations at the lawyer's", do not possess such pragmatics. Their purpose is to clarify the situation, to explain, how to behave in this or that situation. They have no retaliatory force, as codes. This pragmatics imposes restriction on authorship of those texts. The sourcetext can be created by legislative bodies, it is necessary to have certain powers for creation and the statement of such texts. To become a law, the text needs to be ratified. The author-adaptator not necessarily should have the supreme powers for writing adapted text, it is enough to have qualification in the sphere of jurisprudence and necessary knowledge in this sphere.

An adapted legal text can be in the same discourse as its source-text, as it happens to texts of comments to decisions or codes, and can be in the other discourse. For example, such situation is observed at comments of laws by nonspecialists. Thus it is possible to observe that level of awareness of the author-adaptator in legal sphere influences characteristics of the text created. So, we have noted two different comments of Position on housing and communal services - one of them is written by the editor of a magazine who 
studied this question on purpose, probably, having been consulted by the experts. In the other case, it was the text of a person who has left the comment on a forum. It is possible to notice, that if the writer lacks knowledge in the given subject sphere, his secondary text becomes not adaptation, but interpretation.

\section{Conclusion}

Let us note the stylistic features of the legal adapted text. The legal document has the special style, it is defined as legal sub-style within the officiallybusiness style [9: 171]. As it is a style of written speech, it can be characterised by long sentences, complex syntactic structures, and cliches. It is the text for thoughtful reading which means possibility to return to what has already been read. Being aimed at the nonspecialist, the author-adaptator has to consider not only absence of a corresponding professional knowledge of the reader, but also that they can not be used to reading such texts. Adapted legal texts contain shorter sentences and more simple syntactic structures.

If it is the text-reaction which is taken from headings of answers to questions of readers, it is possible to note the conversational style of such texts and an orientation to the addressee. The author-adaptator repeatedly addresses to the potential reader, sometimes using style of everyday speech. Such a feature provokes high emotivity of the adapted legal texts in comparison with their texts-sources. The law text gives an ideal model of the human and institutional relations whereas its adapted text considers its application to real conditions and a concrete situation.

\section{References}

1. Golev, N.D. (1999) Legal aspect of language in linguistics. Legal linguistics: problems and perspectives. Collection of works. Barnaul.

2. Barabash, O.V. (2014) Jurislingvistics: sources, problems, prospects. The bulletin of Penza state university. 2 (6). pp. 14-18.

3. Williams, K. (2012) Legal English and simple English: changes and additions. Legal linguistics. 1 (112). pp. 191-204.

4. Gural', S.K., Smokotin, V.M. (2014) Language of global communication and language and cultural globalization. Language and Culture. 1 (25). pp. 4-13.

5. Ionova, S.V. (2006) Approximation of the content of secondary texts. Philology Dr. Diss. Volgograd. $452 \mathrm{p}$.

6. Pervukhina, S.V. (2012) Coognitive and semantic links of secondary texts and their textssources. The bulletin of Leningrad state university. Philology. 2 (1). pp. 116-125.

7. Arutyunov, H.D. (1999) Language and the world of the human. Moscow: Yazyki russkoj kul'tury. $896 \mathrm{p}$.

8. Naumova, L.A. (1998) Presupposition in the logics and linguistics. Philosophy in search of ontology. 5. pp. 236-255.

9. Bazhanov, S.V., Morohova, O.A. (2006) Legal linguistics and legal language problems. The bulletin of Vladimir state university. 1. pp. 171-175. 